\title{
FEA and Topology Optimization of an Engine Mounting Bracket
}

\author{
Sanket C. Vinchurkar* and P. M. Khanwalkar \\ Mechanical Engineering Department, Savitribai Phule Pune University, Pune, Maharashtra, India \\ Accepted 15 June 2016, Available online 20 June 2016, Special Issue-5 (June 2016)
}

\begin{abstract}
The main purpose of an engine mounting bracket is to support the power -train system in an Automobile in all conditions of road surfaces including even, uneven road surfaces. It is very difficult to change the supporting locations and the types of support after the engine is built, the mounting brackets must be verified in the design stage. This paper contains the study of Design and Optimization of an engine mounting bracket and comparison between existing and optimized engine mounting bracket. CAD model has been generated through reverse engineering. The bracket of Mahindra Scorpio Engine is to be taken for study. After analyzing the engine mounting bracket of Mahindra Scorpio, Optimization is done.
\end{abstract}

Keywords: Topology optimization, Engine mounting bracket, Finite element analysis.

\section{Introduction}

An engine mounting bracket which is used to hold the power-train system. An Engine mounting bracket generally mounted on Chassis of vehicle. In a typical car, the power-train (engine) and transmission are bolted together and held in place by three or four mounts. If mounting bracket does not have any appropriate stiffness then it can causes noise and vibration. That vibrations generally passed from mounting to the body which causes body vibration. A weak bracket can also lead to rolling vibration of the engine shock from deceleration and acceleration. Because of this factors, it is quite important that the mounting bracket have enough stiffness and strength. Strength analysis needs to be performed to verify the bracket properties early in the design stage. The strength analysis computes the magnitude of a load from the mass of the engine, including the factor of safety (FOS), and applies this load to each engine mounting bracket which is mounted in this engine. The stress analysis performed with these boundary conditions and the analyst verifies that results are within an acceptable range.

One of the research paper has observed that, failure is occurs at the ribs end. From this study, it is observed that, stress difference between the simulation approach and physical testing is about $18 \%$. From the field failure results and the results of Hyper Works, it is observed that, failure occurs where the ribs end on the bracket. To reduce the stress level at that section, additional supported ribs are provided on the top of

*Corresponding author: Sanket C. Vinchurkar the bracket. So that the overall stiffness increases (Koushik. S., 2013).

One author having Present work deals with FEA analysis of engine mounting bracket. It includes the modelling of the mounting brackets by changing the particular existing material of component. Materials selected for mounting bracket are magnesium alloy and aluminium alloy. Analysis of bracket includes Static analysis and Modal Analysis of bracket using a square cross section. The study shows that this bracket will have a better weight reduction compare to standard aluminium alloy material and withstand high stress. It has been concluded that magnesium can be preferred over aluminium as a material for an engine mounting bracket. Mounting bracket having magnesium material is better in various operating condition (P. D. Jadhav, Ramakrishna, 2014).

One of the paper have concentratly focuses on natural frequency. Engine is one of the most important components of a road vehicle such as car. Vibration plays an important role in Engine components, especially in the supporting mounting bracket. If the vibrations and stresses are excessive then there may be the chances of the structural failure of mounting bracket. It is a significant study which requires indepth investigation in order to understand the structural characteristics and its dynamic behavior of bracket. This current paper presents and focuses on some Finite Element analysis (FE) of a typical engine bracket of a car will be carried out and natural frequency will be determined. Gray Cast Iron is a brittle material and this is evident in the results that the low natural frequency will prove as a obstacle in vibration characteristic of the bracket. Among the Al alloy and 
mg alloy having near about same natural frequency but they select gray cast iron as a material. In Practical terms, Mg alloy exhibits better damping characteristics than $\mathrm{Al}$ alloy. Hence as far as the recommendation goes, Mg alloy will be preferred (V. Doundkar et al, 2011).

Abdolvahab Agharkakli have summarizes the actual methodology to calculate the linear mount characteristics with the help of mathematical models and comparison of these results with results from MATLAB simulations. The mounts are treated at the component level, and mathematical models for the same are evaluated to get the required characteristics. The mounts are modelled as spring and damper system subjected to impact loading that occurs at the time of crash events. The approximation of input pulse has been described mathematically, which then serves to find the characteristics of the mounts. The change in the characteristics of mounts with the change in the velocity of impact has also been studied (A. Agharkakli, D. P. Wagh, 2013).

R. Singh is focus on Dynamic design and vibroacoustic modelling are illustrated via two case studies. The first case study, it examines the role and performance of adaptive and passive hydraulic engine mounts. In the second case study, the importance of adhesives and welded joints in vehicle bodies and chassis structures is highlighted via generic ' $\mathrm{T}$ ' and ' $\mathrm{L}$ ' beam assemblies. In each case, experimental and analytical results are presented. Unresolved research issues are briefly discussed (U. S. Ghorpade, 2012).

\section{Problem statement}

As per as automobile is concerned, engine is considered as most imp part and driving sources and the important part and driving sources and the improvement in the engine mounting bracket is taken as the essential topic of research for many years.

We can see that in the case of existing mounting bracket there is usual break down of the bracket due to vibrations of the engine at different speed and load condition and also due to vehicle driving road conditions.

In this paper, we performed about the static analysis for the existing mounting bracket with all constant dimensions then all the FEA results are observed and analyzed then some modifications is done in the design of existing mounting bracket however, the result shows that there is a significant reduction of in the weight with marginal increasing stress value.

\section{Methodology}

- $\quad$ CAD model generation of existing bracket

- Meshing and analysis of existing bracket

- Optimization of existing bracket

- Meshing and analysis of optimized bracket

- Comparison of existing bracket and optimized bracket

\section{Generation of CAD model}

The Engine mounting bracket is consisting of two parts, which is nothing but inner and outer part. CAD model then is made by the commands in CATIA i.e. Pad, fillet, pocket and geometrical selections in part design module. Parametric generation of drawings will help to get the dimensions useful in forces calculations in static loading conditions on a component. Following CAD model of existing bracket is generated in CATIA We used CATIA V5R19 for generation of existing CAD model. Figure 1 shows existing engine mounting bracket.

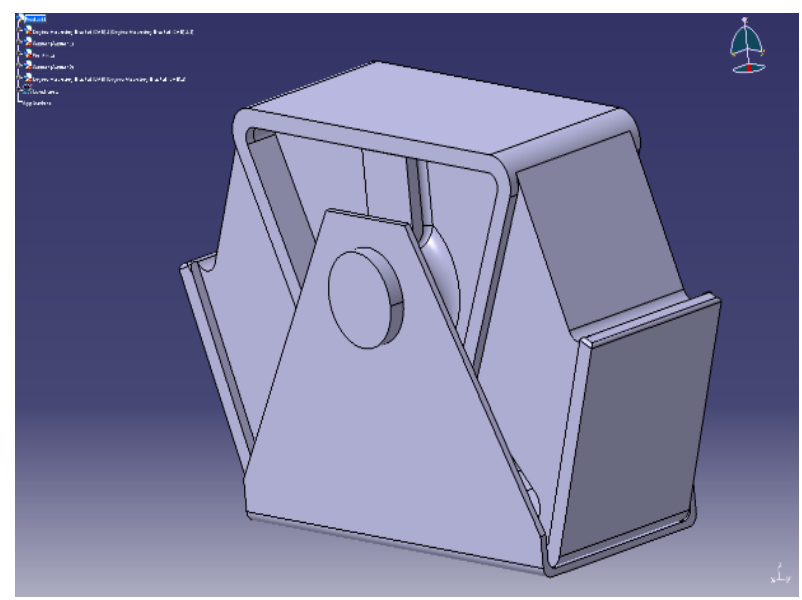

Fig. 1: Existing engine mounting bracket drawn in CATIAV5R19

\section{Static Structural Analysis}

The required information for analysis of an Engine mounting bracket is as below:

4.1 Material properties: The value of poisons ratio, young's modulus, density, yield strength for mild steel are taken.

4.2 Meshing: It is required to generate solid element mesh. Meshing of the bracket is done as a tetra-hedral mesh with 54829 as Number of Nodes and 232277 as numbers of elements.

4.3 Load: The load is to be consider which is greater than the weight of engine. The load is taken as $1500 \mathrm{~N}$.

4.4 Constraints: The nodes around the bracket mounting holes have a rigid element connecting them to the center of the hole which has of its degree of freedom fixed. The element which is used to fix bracket and body of the vehicle is fixed by constraining six DOF (Degree of freedom).

FE mesh with the loads and constraints is made in the meshing. Solver deck is prepared for carrying out static analysis. The geometry is exported to $\mathrm{db}$ format to run into ANSYS. The post processing is done in ANSYS 


\section{Boundary Conditions}

After meshing is completed we apply boundary conditions. These boundary conditions are the reference points for calculating the results of analysis. We used Hypermesh 0.12. In this, the bottom side of bracket is said to be a constraint and $1500 \mathrm{~N}$ load is apply on bracket. Figure 2, shows the Constraints and forces applied on model in Hypermesh. After that, analysis is done.

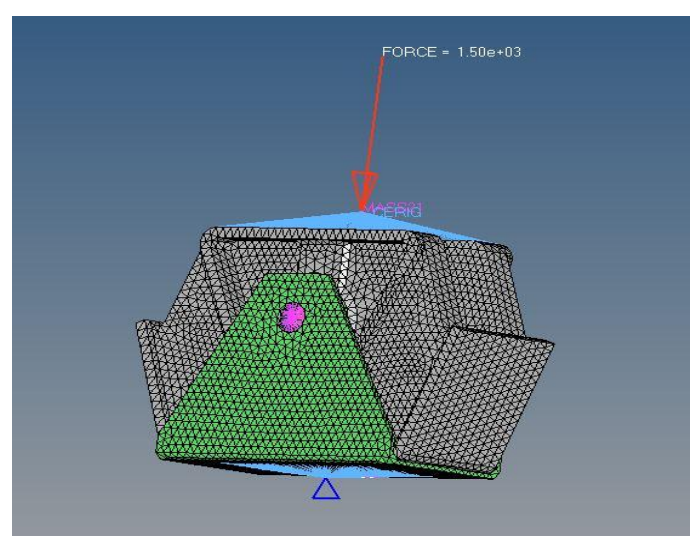

Fig. 2: Constraints and forces applied on existing model in Hypermesh

The material for bracket is used as mild steel. The properties of mild steel are listed below,

Table 1: Properties of mild steel

\begin{tabular}{|c|c|}
\hline Property & Value \\
\hline Young's Modulus, $(\mathrm{E})$ & $2.1 \times 10^{5} \mathrm{MPa}$ \\
\hline Poisson's Ratio,$(v)$ & 0.3 \\
\hline Density, $(\rho)$ & $7850 \mathrm{~kg} / \mathrm{m}^{3}$ \\
\hline Yield Stress, $\left(\sigma_{\text {yield }}\right)$ & $290 \mathrm{MPa}$ \\
\hline Ultimate Tensile Stress, $\left(\sigma_{\text {uts }}\right)$ & $390 \mathrm{MPa}$ \\
\hline
\end{tabular}

For post processing, we used ANSYS 13. Following are the result for Post processing, Figure 3 shows the maximum Stress value obtained for engine mounting bracket is $65.16 \mathrm{~N} / \mathrm{mm}^{2}$ which is well below the critical value. Hence, design is safe.

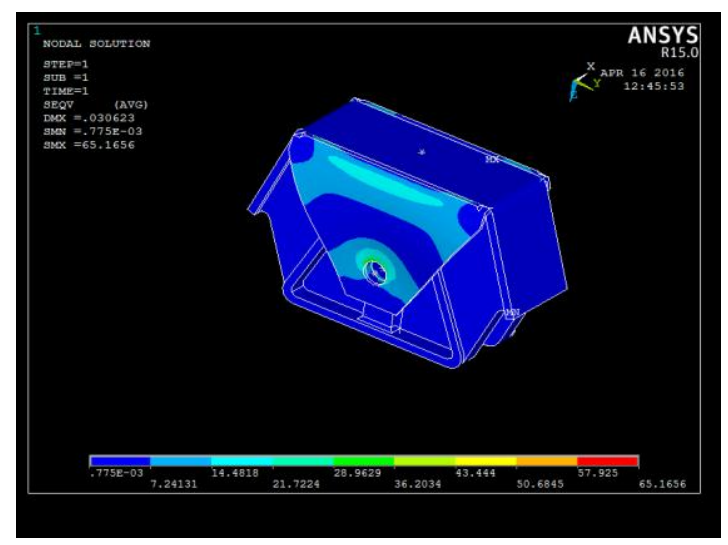

Fig. 3: von-mises stress for existing mounting bracket
In the figure 4 , the deformation for engine mounting bracket is $0.03 \mathrm{~mm}$.

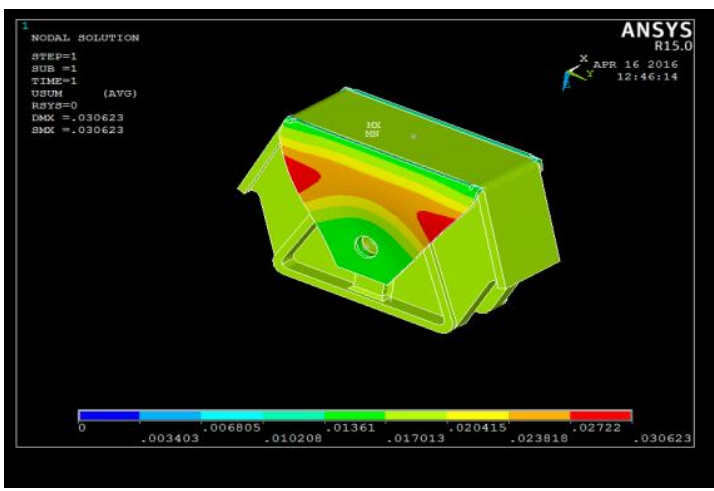

Fig. 4: Deformation plot for existing engine mounting bracket

In figure 5, the actual mass of an existing engine mounting bracket is observed as $2.83 \mathrm{~kg}$.

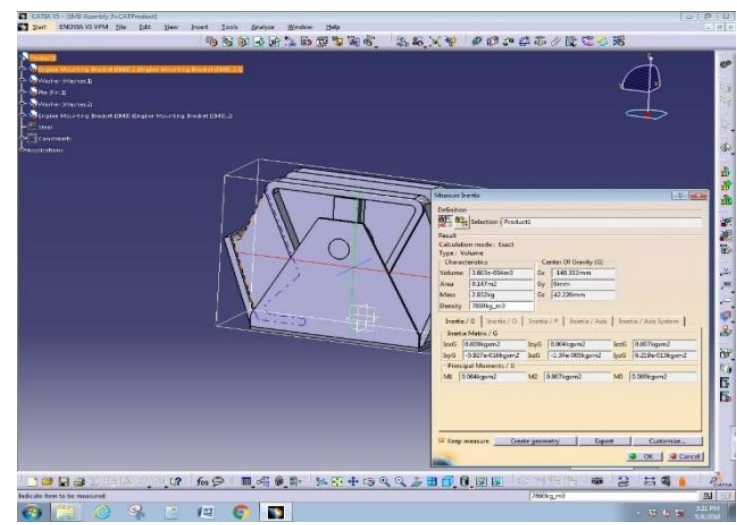

Fig. 5: Mass of model calculated in CATIA for existing engine mounting bracket

\section{Topology Optimization}

Topology optimization is an optimization process which gives the optimum material layout according to the design space and loading case. Two elongated holes are generated on engine mounting bracket which is shown in figure 6.

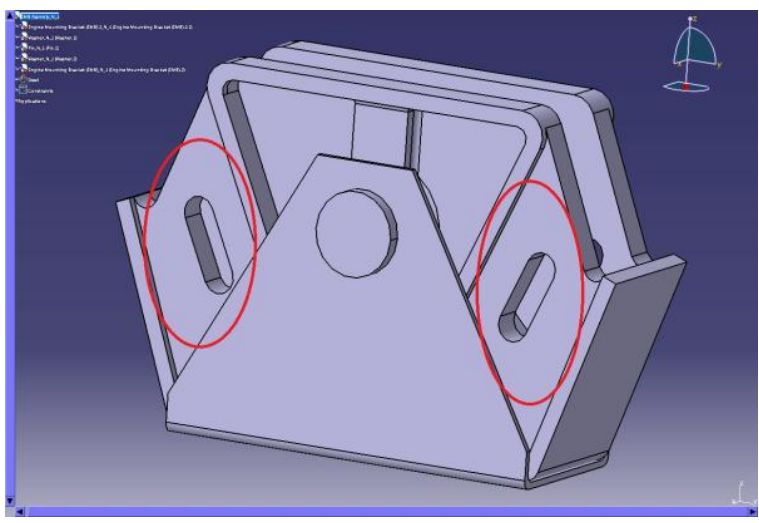

Fig. 6: CAD model of optimized Engine mounting bracket consisting 
For meshing of optimized engine mounting bracket, we used Hypermesh 12.0. The number of nodes are 68035 and Number of elements are 35521.

Figure 7 shows that, Meshed model and boundary condition application for optimized engine mounting bracket.

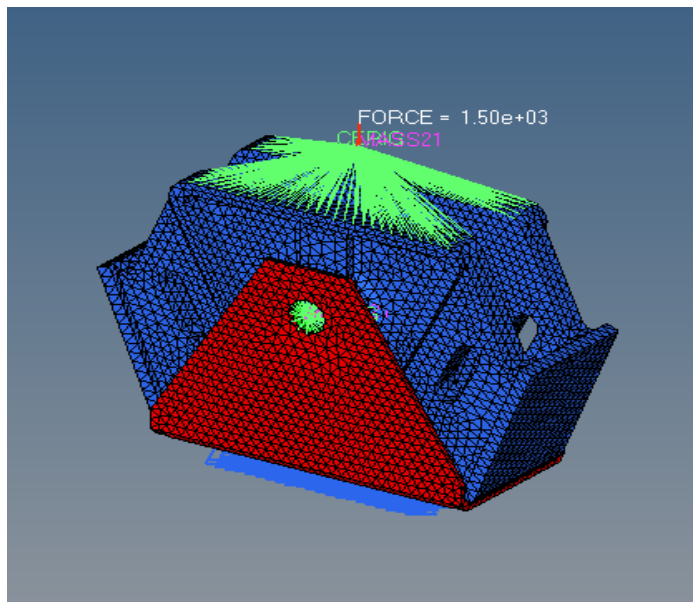

Fig. 7: Meshed model and boundary condition application for optimized bracket

Following are the results displayed for stress and deformation (MS):

In figure 8, Stress value for engine mounting bracket is $67.16 \mathrm{~N} / \mathrm{mm}^{2}$ which is well below the critical value. Hence, design is safe.

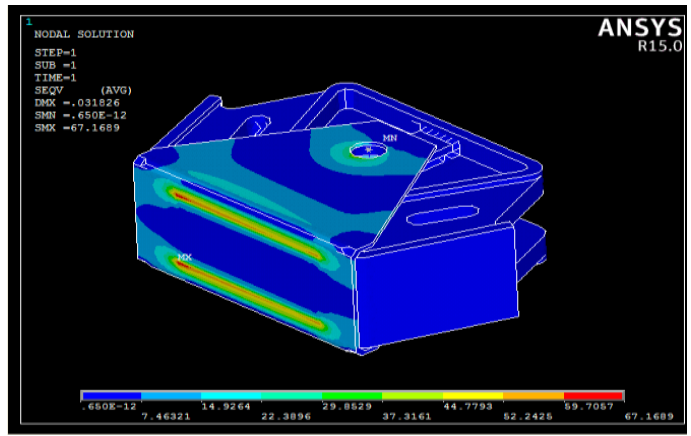

Fig. 8: von-mises stress plot for optimized engine mounting bracket

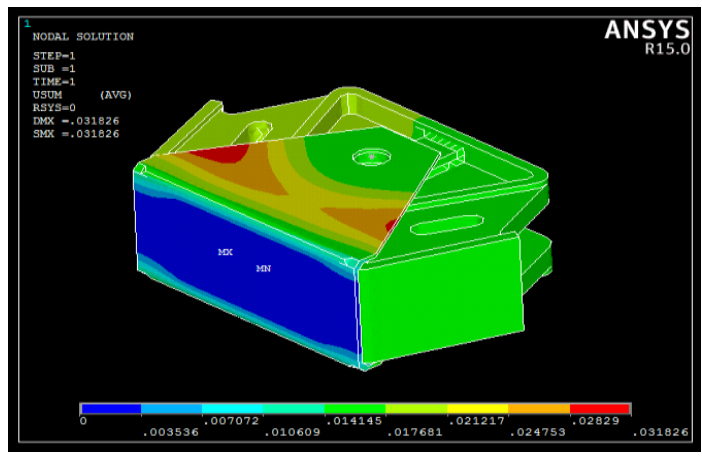

Fig. 9: Displacement result for engine mounting bracket
Figure 9 shows, deformation for optimized engine mounting bracket is $0.03 \mathrm{~mm}$.

In figure 10 , the mass of engine mounting bracket is $2.73 \mathrm{~kg}$.

Weight $=$ mass $\times \mathrm{g}$

$$
\begin{aligned}
& =2.73 \times 9.81 \\
& =26.78 \mathrm{~N}
\end{aligned}
$$

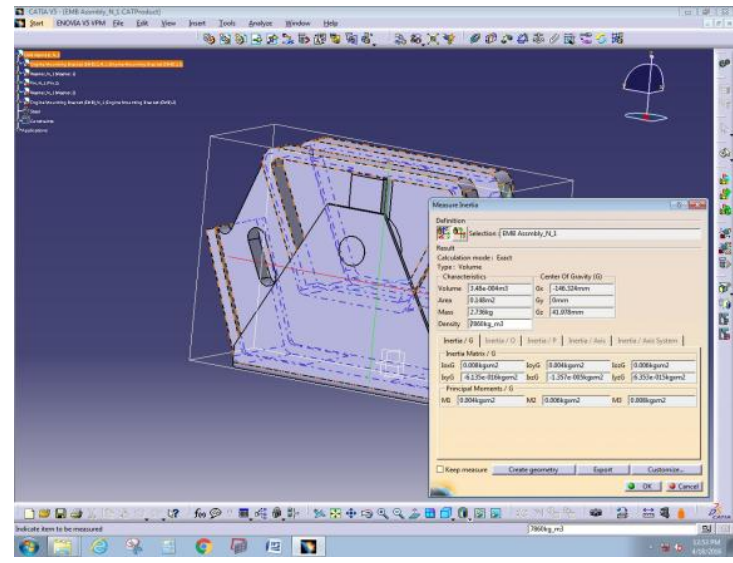

Fig. 10: Mass of model calculated in CATIA

\section{Result and discussions}

From the Finite element analysis of existing bracket, we observed that the maximum stress value comes out to be $65.16 \mathrm{~N} / \mathrm{mm}^{2}$ but after optimization, it is observed that $67.16 \mathrm{~N} / \mathrm{mm}^{2}$. The deformation for existing and optimized engine mounting bracket is same as $0.03 \mathrm{~mm}$ which is also very less. The calculated mass of existing engine mounting bracket is $2.83 \mathrm{~kg}$ but after optimization it observed that $2.73 \mathrm{~kg}$.

Table 2: Comparison between existing and optimized engine mounting bracket

\begin{tabular}{|c|c|c|c|}
\hline & Stress & Deformation & Mass \\
\hline $\begin{array}{c}\text { Existing } \\
\text { bracket }\end{array}$ & $65.16 \mathrm{~N} / \mathrm{mm}^{2}$ & $0.03 \mathrm{~mm}$ & $2.83 \mathrm{~kg}$ \\
\hline $\begin{array}{c}\text { After } \\
\text { Optimization }\end{array}$ & $67.16 \mathrm{~N} / \mathrm{mm}^{2}$ & $0.03 \mathrm{~mm}$ & $2.73 \mathrm{~kg}$ \\
\hline
\end{tabular}

Design of bracket and its comparison is done by calculation is as follows:

Percentage decrease in mass $=$

$=\frac{\text { mass of existing bracket-mass optimised bracket }}{\text { mass of existing bracket }}$

$$
=\frac{2.83-2.73}{2.83} \times 100=3.53 \%
$$

Hence, from the calculation we conclude that, the decrease in weight after optimization is $3.53 \%$.

\section{Conclusion}

After the optimization of an engine mounting bracket, we conclude that, 
1) By generating the two elongated holes, the material of an engine mounting bracket was saved.

2) Thus the weight and cost of the mounting bracket automatically reduces.

\section{References}

Koushik. S. (2013), Static and Vibration Analysis of Engine Mounting Bracket of TMX 20-2 using OptiStruct, Altair Technology Conference 2013, India

P. D. Jadhav, Ramakrishna(2014), Finite Element Analysis of Engine Mount Bracket, International journal of advancement in engineering technology, 1, 2349-3224

V. Doundkar, D. Ghatage, M. Madkaikar, A. Kulkarni, (2011), Topology Optimization for Engine Mounting Arm with Fatigue, HTC 2011
A. Agharkakli ,D. P. Wagh (2013), Linear Characterization of Engine Mount and Body Mount for Crash Analysis, International Journal of Engineering and Advanced Technology, 3, 2249 - 8958

Singh R.(2000), Dynamic design of automotive system: Engine mounts and structural Joints, 25, 319 - 330.

Y. Basavaraj, T.H, Manjunatha (2013), Design Optimization of Automotive Engine Mount System, International Journal of Engineering Science Invention, 2, 2319 - 6734

U. S. Ghorpade, D. S. Chavan, V. Patil, M. Gaikwad, (2012), Finite Element Analysis and Natural Frequency Optimization of Engine Bracket, International Journal of Mechanical and Industrial Engineering, 2, 2231 -6477 